\title{
Pattern and Trend of Malaria Morbidity and Mortality in Tigray Region, Ethiopia from 2011/12-2014/15 \\ Hadgu Gerensea ${ }^{1 *}$ and Hafte Teklay ${ }^{2}$
}

${ }^{1}$ School of Nursing, College of Health Science and Referral Hospital, Axum University, Axum, Tigray, Ethiopia

${ }^{2}$ Departemnt of Bio-medical Sciences, College of Health Science and Referral Hospital, Axum University, Axum, Tigray, Ethiopia

\begin{abstract}
Introduction: Malaria is vector borne disease. Even though there is global step-down in malaria mortality still the African Region still continues to shoulder the heaviest burden: In 2015, this region accounted just about nine in ten malaria cases and deaths world-wide.

Methods: The primary intention of this work was to evaluate four year pattern and trends of malaria morbidity and mortality in Tigray region using backward study system from patients' enrollment and Health Management Information System (HMIS) data. The data was interred and coded to Epi Info and exported to SPSS version 21 for statistics analysis.

Results: A total of 1.5 million malaria cases were analyzed. $78 \%$ of the cases were confirmed though liberator where as $22 \%$ of the cases diagnosis were made though clinical manifestation without liberator. The most common species of malaria morbidity is Plasmodium falciparum which accounts $71 \%$ where are the rest were other species. Morbidity in $2014 / 15$ is $33 \%$ lower than $2011 / 12$, mortality is $43 \%$ lower than $2011 / 12$.

Conclusion: Although elimination and eradication were not possible, reduction of malaria morbidity and mortality were achieved. But still know it needs high-level and uninterrupted political loyalty and changeless attention, deep programmatic attempts in affected arena for eradication and riddance of malaria.
\end{abstract}

Keywords: Impact; Vector born; Plasmodium falciparum; Eradication

Abbreviations: TRHB: Tigray Regional Health Bureau; HMIS: Health Management Information System; IPD: Inpatient Department; OPD: Outpatient Department; RDT: Rapid Diagnostic Test; $P$. falciparum: Plasmodium falciparum; P. Vivax: Plasmodium vivax; IRB: Institutional Review Board

\section{Introduction}

Malaria is a very serious public health problem and most important vector borne disease in most developing countries. According to World Health Organization report half of the world population are at risk of malaria with almost all African population [1-3]. Worldwide forward motion in malaria control masks disparities between and within countries. The African Region still continues to shoulder the heaviest burden: In 2015, this one Region accounted for approximately nine in ten malaria cases and deaths world-wide [4].

Local outbreaks are common and the dispersion differs from spot to spot depending on environmental condition and altitude. In Ethiopia malaria is a leading concern since it is one of the primary origins of morbidity and mortality. Despite the actual efforts to control malaria in Ethiopia, the condition has not better principally due to the increasing problems of parasite resistance to the relatively inexpensive antimalarial drugs, vector resistance to insecticides, low coverage of malaria impeding service $[5,6]$.

Worldwide Malaria mortality has been declined $42 \%$ since 2000 . In which Africa contributes $49 \%$ reduction due to prevention and control measures, 2-3 but in 2010 still $90 \%$ malaria death occurred in Africa mostly in under five year age which accounts $24 \%$ of the cause of mortality [3,7].

Similarly in 2002 and 2012 Global reports shows $90 \%$ and $80 \%$ of deaths are from Africa [1,8]. Moreover in 2015 Africa accounted for close to nine in ten malaria cases and deaths worldwide. Malaria is still headache for African countries even there is disparities between and within state [4].

\section{Materials and Methods}

\section{Study area and period}

The study was performed in Tigray region that covers an area of 109 square kilometers and its elevation is 2,084 meters above sea level. The region has 18 public hospitals and 170 health centers with total population of 4,316,988 [9-12].

\section{Study design}

Retrospective study design from August 2011 up to August 2015 were used to speech act the pattern and direction of malarial morbidity and mortality.

\section{Sample size}

All the four year information of public hospitals and health centers of Tigray region were taken.

\section{Data collection procedures and instrument}

Data extraction tool was formed to extract information from HMIS registration.

*Corresponding author: Hadgu Gerensea, School of Nursing, College of Health Science and Referral Hospital, Axum University, Axum, Tigray, Ethiopia, Tel: +251914388918; E-mail: hadguellen1@gmail.com

Received March 24, 2017; Accepted April 17, 2017; Published April 24, 2017

Citation: Gerensea H, Teklay H (2017) Pattern and Trend of Malaria Morbidity and Mortality in Tigray Region, Ethiopia from 2011/12-2014/15. J Bioanal Biomed 9: 114-117. doi:10.4172/1948-593X.1000163

Copyright: (ㄷ 2017 Gerensea H, et al. This is an open-access article distributed under the terms of the Creative Commons Attribution License, which permits unrestricted use, distribution, and reproduction in any medium, provided the original author and source are credited. 
Citation: Gerensea H, Teklay H (2017) Pattern and Trend of Malaria Morbidity and Mortality in Tigray Region, Ethiopia from 2011/12-2014/15. J Bioanal Biomed 9: 114-117. doi:10.4172/1948-593X.1000163

\section{Data analysis}

First the data was entered and coded to Epi info version 3.5.4 and exported to analyses in to SPSS version 21 window 7. Data analyses included descriptive statistics was used to describe participants' demographic characteristics and trend of malaria mortality and morbidity.

\section{Data quality management}

Data was extracted by statistician from HMIS data of Tigray region with direct oversight.

\section{Ethical clearance}

Institution Review Board (IRB) of Aksum University, College of Health Science was examined the code of conduct to guarantee full security of the rights of study subordinates. Pursuing the approval by IRB of Aksum University, IRB of Tigray Region Health bureau also authorized and authoritative letter of co-operation was written to the directorate of health information system. In order to keep privacy of any data obtained, the data aggregation procedure was treated nameless.

\section{Availability of data and material}

The data and materials used for analysis and draw conclusion are available at the supplementary data.

\section{Results}

\section{Scio-demographic}

The study was conducted in all public hospitals and Woreda health offices (170 health center) of Tigray region. An entire of 1.5 million cases of malaria was taken out from IPD (inpatient department) and OPD HMIS data. From the total participants in the data $1,515,483$ $(68.8 \%)$ were male. No data was leaving out since each was absolute and clear (Table 1).

\section{Pattern of malaria morbidity and mortality}

$78 \%$ of the cases were confirmed though liberator where as $22 \%$ of the cases diagnosis were made though clinical manifestation without liberator. The most common species of malaria morbidity is Plasmodium falciparum which accounts $71 \%$ where are the rest were other species. Similarly $43 \%$ of mortality of malaria were diagnosed by clinical without liberator but the rest were diagnosed both clinical and confirmed though liberator. More over $76 \%$ of the deaths were related to P. falciparum (Figures 1 and 2).

\section{Trend of malaria morbidity and mortality}

The trend of malaria morbidity is decreasing every year. Morbidity in $2014 / 15$ is $33 \%$ lower than $2011 / 12$, mortality is $43 \%$ lower than 2011/12 (Figures 1 and 2).

\section{Discussion}

Even though there is no full data and sufficient information of identification of malaria registry in Ethiopia so far, starting from 2011/12 HMIS was initiated. There is also lacking registration of death document and an underestimation of Malaria mortality in Ethiopia. In the absence of certain population enrollment in developing countries like Ethiopia using HMIS is the only accessible frame to detect the

\begin{tabular}{|c|c|c|c|c|c|}
\hline \multicolumn{6}{|c|}{ Age } \\
\hline & & $<5$ years & $5-15$ years & $>15$ years & Total \\
\hline \multirow[t]{2}{*}{ Sex } & Male & 98867 & 178870 & 765093 & 1042830 \\
\hline & Female & 79244 & 121753 & 271656 & 472653 \\
\hline \multicolumn{2}{|c|}{ Total } & 178111 & 300623 & 1036749 & 1515483 \\
\hline
\end{tabular}

Table 1: Socio-demographic characteristics of participants.

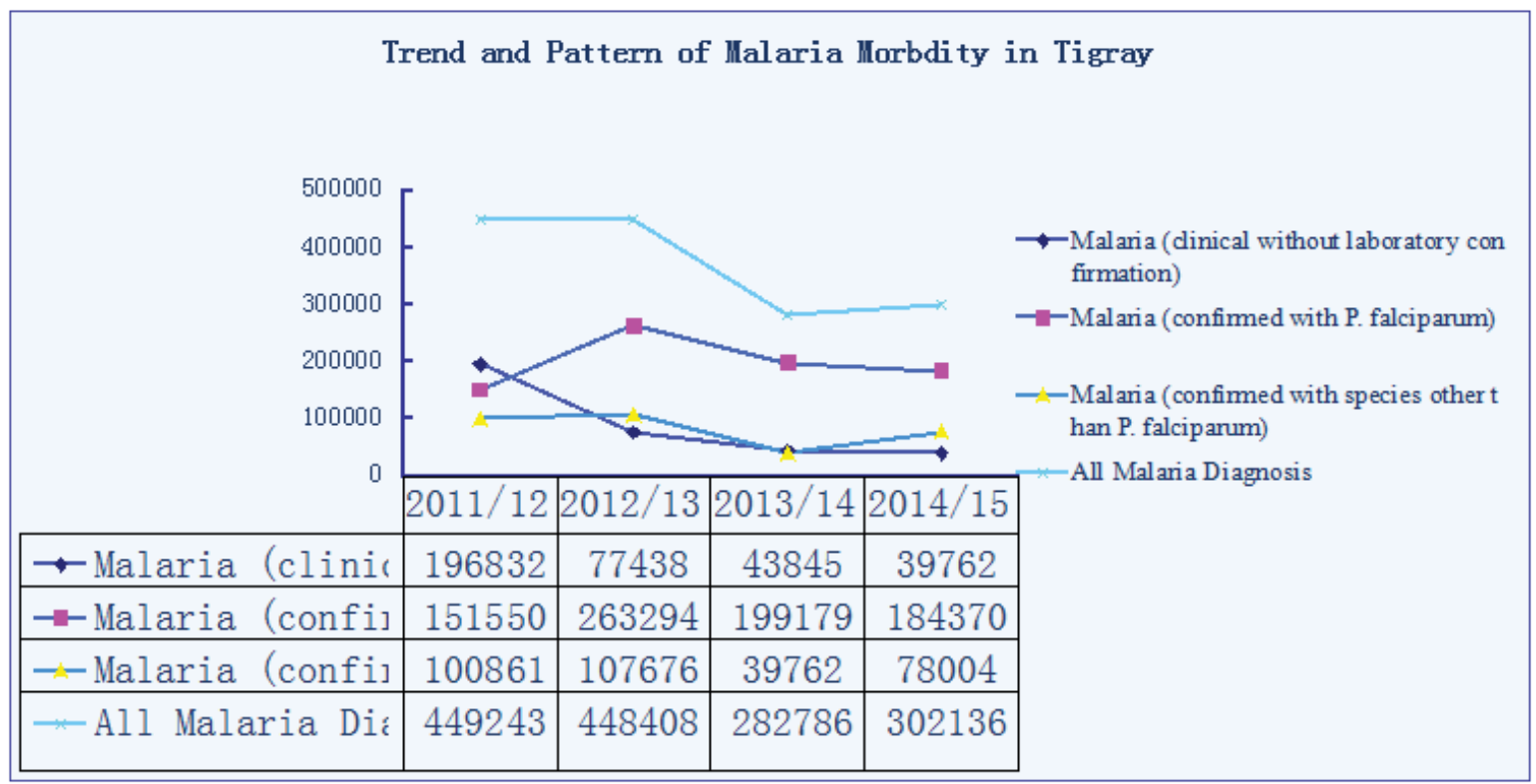

Figure 1: Trend and pattern of malaria morbidity in Tigray Region, Ethiopia from 2011/14-2014/15 


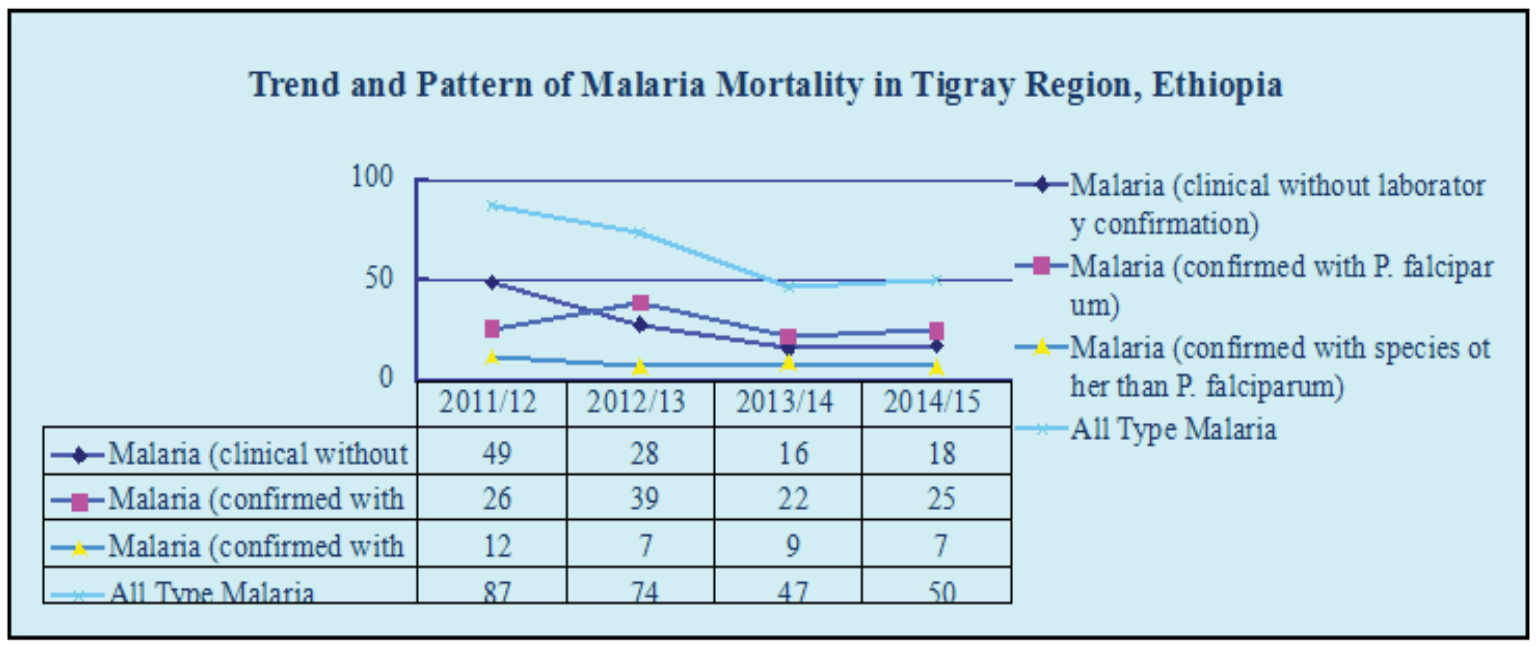

Figure 2: Trend and pattern of malaria mortality in Tigray Region, Ethiopia from 2011/14-2014/15.

direction and pattern of malaria morbidity and mortality in Tigray region [9-11].

Worldwide Malaria mortality has been declined $42 \%$ since 2000 . In which Africa contributes $49 \%$ reduction due to prevention and control measures [2-3]. Similarly this study also shows decline in the four year trend by $43 \%$ which indicates some improvement in the bar and control of malaria. Not only prevention and control it also shows improvement in early sensing and control of malaria. This achievement may be resulted from enhanced political engagement, the growth of regional inaugural and improved tool. But still know the Prevention and control strategy did not achieve the World Health Organization (WHO) established the Global Malaria Eradication Programme [4].

The Result also shows Plasmodium falciparum is the most common cause of malaria morbidity which is consistent with world health report of 2002. Moreover the trend of $P$. falciparum increase unlike $P$. vivax which is comparable with the study conducted in general hospital of Ethiopia [13]. This may be related with the availability of Rapid Diagnostic Test (RDT). Similarly the study also shows decrease malaria morbidity and mortality with clinical diagnosis without liberator.

The study indicates morbidity of malaria decreased by $33 \%$. This is similar with the study conducted in Mbakong have shown an unsteady, but declining direction over the last seven years with a practically pertinent meaning [14]. This may be achieved due to the National Goals and Targets of the President's Malaria Initiative to reduce malaria mortality in Ethiopia by $50 \%$ by the end of a three-year project period [15].

\section{Conclusion}

Although elimination and eradication were not possible, reduction of malaria morbidity and mortality were achieved. But still know it needs high-level and sustained political commitment and constant vigilance, intense programmatic efforts in affected areas for eradication and elimination of malaria. More over best strategies should be shared from countries of free malaria.

\section{Limitation of the Study}

Data from health facilities are potentially useful for monitoring time trends in the number of malaria cases and deaths but have severe limitations. Analysis was based on routinely collected clinical malaria data from public health institution. There is a possibility of both under and over reporting of malaria cases due to other febrile illnesses which mimic with malaria. Since retrospective data were used its accuracy and completeness could not be fully verified. Reporting from facilities to districts and from districts to the ministry of health varies in its completeness and timeliness from institution to institution and often does not include non-government facilities.

\section{Acknowledgment}

My deepest gratitude goes to Aksum University and TRHB for giving full data and supportive materials and information.

\section{Author Contributions}

Hadgu Gerensea conceived and designed the study, analyzed the data and wrote and approved the final manuscript.

Hafte Teklay analysed the data and wrote and approved the final manuscript.

\section{References}

1. World Health Organization (WHO) (2013) World Malaria Report 2013. World Health Organization: Geneva.

2. World Health Organization (WHO) (2014) World malaria report 2012. Geneva: World Health Organization pp: 1-276.

3. World Health Organization (WHO) (2013) World malaria report 2013 shows major progress in fight against malaria, calls for sustained financing.

4. World Health Organization (WHO) (2016) Report GMP Eliminating malaria.

5. Deressa W, Olana D, Chibsa S (2004) Magnitude of malaria admissions and deaths at hospitals and health centers in Oromia, Ethiopia. Ethiop Med $\mathrm{J} 42$ 237-246.

6. Nigatu A, Homa G, Getachew D, Gelaw S, Andersson S, et al. (2014) Can training Health Extension Workers in the integrated pharmaceutical logistics system (IPLS) be effective, affordable and opportunistic? Ethiop Med J 52: 11.

7. Murray CJ, Rosenfeld LC, Lim SS, Andrews KG, Foreman KJ, et al. Globa malaria mortality between 1980 and 2010: a systematic analysis. Lancet 379: 413-431.

8. World Health Organization (WHO) (2002) The World Health Report 2002: reducing risks, promoting healthy life.

9. Gerensea $H$ (2017) Trend and pattern of neonatal morbidity and mortality in Tigray Region, Ethiopia. Edorium J Pediatr 1: 1-5.

10. Hadgu G, Almaz S, Murugan R, Sisay S, Mebrahtu A, et al. (2017) Comparison of Body Temperature Between $5 \mathrm{~min}$ and $10 \mathrm{~min}$ Glass Mercury Thermometers 
Citation: Gerensea H, Teklay H (2017) Pattern and Trend of Malaria Morbidity and Mortality in Tigray Region, Ethiopia from 2011/12-2014/15. J Bioanal Biomed 9: 114-117. doi:10.4172/1948-593X.1000163

in Under-5 Children in Axum Saint Mary Hospital, Central Zone of Tigray, Ethiopia. AJMMS 5: 10-19.

11. Silassie AG, Giorgis MW, Kahsay N, Fisaha Y, Zerihun Z, et al. (2016) Knowledge, Attitude and Practice of Condom Utilization among Axum Preparatory School Students. J AIDS Clin Res 7: 560.

12. Gerensea H, Murugan R (2016) Is There Significant Difference between Digital and Glass Mercury Thermometer? Adv Nurs 2016: 10.
13. Ramos JM, Reyes F, Tesfamariam A (2005) Change in Epidemiology of Malaria Infections in a Rural Area in Ethiopia. J Travel Med 12: 155-156.

14. Ndong IC, van Reenen M, Boakye DA, Mbacham WF, Grobler AF (2014) Trends in malaria admissions at the Mbakong Health Centre of the North West Region of Cameroon: a retrospective study. Malar J 13: 328.

15. Adugna A (2014) Vectored Infectious Diseases: Malaria in Ethiopia. 